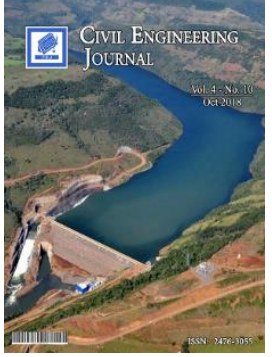

\title{
Investigating Effects of Coal Flotation Waste on Aged Hot Mix Asphalt Performance
}

\author{
Mohammadreza Abbastabardelavar ${ }^{\mathrm{a} *}$, Amir Izadi ${ }^{\mathrm{b}}$, Fereshte Asadiamiri ${ }^{\mathrm{c}}$ \\ ${ }^{a}$ MSc, Shomal University, Amol, Mazandaran, 4616184596, Iran. \\ ${ }^{b}$ Assistant Professor, Shomal University, Amol, Mazandaran, 4616184596, Iran. \\ ${ }^{c}$ MSc Student, Shomal University, Amol, Mazandaran, 4616184596, Iran.
}

Received 11 April 2018; Accepted 02 October 2018

\begin{abstract}
The present study was an attempt to investigate the effect of fresh and old coal flotation waste (coal waste), used as asphalt filler and additive, on the properties of hot asphalt mixtures in aged and un-aged condition. In this experimental study, fresh and old coal flotation waste, obtained from the Central Alborz Coal Washing Plant, were used to produce filler specimens (100\% Wt.) as substitutes for limestone powder and asphalt additive (7\% w.t). Finally, the performance of the asphalt mixture containing flotation waste was evaluated using Marshall Stability and indirect tensile tests. The aforementioned compounds were used to produce specimens under short-term aging conditions and the results were compared with other results obtained under un-aged condition. The results indicate that flotation waste improved performance of hot mix asphalt under short-term aging conditions.
\end{abstract}

Keywords: Flotation Waste; Coal Waste; Aging; Asphalt Performance.

\section{Introduction}

The increasing demand for traffic and licit axial load calls for improvements in the materials used in pavement construction. One of the main goals of pavement designers is to construct a safe, cost-effective, durable and smooth pavement that can withstand expected traffic and loads. In order to achieve this goal, experts, researchers and engineers seek pavement materials to minimize failures and enhance pavement performance [1]. Considering the high cost of road construction, studies need to be focused on accurate designs and selection of cost effective materials that can increase the efficiency and life cycle of the roads at the same time [2]. Fillers, as one of the most important components of asphalt mixtures, play an important role in determination of asphalt mixtures' properties and performance in general, and the viscidity, aggregate interlock and filling the gap between aggregates in particular. Moreover, Fillers can affect liquidity, moisture susceptibility, stiffness, durability, fatigue life, and rutting of asphalt mixing [3]. Due to reduction of natural resources, increasing development of construction and civil activities, need for energy saving and environmental impacts, researchers are looking for a good alternative for road construction materials.

Asphalt pavements are exposed to a variety of destructive factors which lead to reduction of their shelf life over time. Considering the high cost of pavement building operations, some necessary measures should be taken to avoid asphalt destruction and mitigate pavement failures.

\footnotetext{
* Corresponding author: m.abastabar@yahoo.com

dol) http://dx.doi.org/10.28991/cej-03091175

> This is an open access article under the CC-BY license (https://creativecommons.org/licenses/by/4.0/).

(C) Authors retain all copyrights.
} 
Aging is one of the most important and effective factors in the asphalt mixture failure. Aging in asphalt mixtures could be attributed to bitumen aging. Unfortunately, the chemical composition of bitumen tends to change over time, and this leads to a loss of bitumen efficiency. In other words, aging occurs as a result of changes in the structure or composition of bitumen mainly due to the temperature and oxygen effects, which results in hardening and consequently, brittleness of bitumen. Aging mechanism can be described as evaporation of hydrocarbon particles at high temperatures and cleavage of intermolecular bonds, transformation of them into a new molecular structure, and oxidation [5].

Aging consists of 2 stages: short-term aging and long-term aging. Short-term aging occurs during asphalt mixing, transportation, laydown and compaction, due to the asphalt exposure to high temperature. Long-term aging occurs over time, due to the fact that bitumen grows harder during its service life. Oxidation and evaporation of bituminous compounds are two main effective factors in long-term aging of asphalt. Many reports have been released on the problems associated with early aging of asphalt mixtures. The problem starts when bitumen hardening, due to aging, leads to increased stiffness of asphalt mixture, reduced asphalt strain, and increased cracking, and finally exposes the asphalt mixture to failure [6].

Recycling of materials obtained from the extraction of some primary materials in factories is mainly a challenge for the owners of industries, including the coal industry. The extraction and processing of coal is accompanied by production of a considerable amount of waste materials. Considerable amount of waste is produced and accumulated during coal mining and coal processing [7, 8]. Modarres et al. (2014) investigated the use of coal powder ash, obtained from burning coal at $750^{\circ} \mathrm{C}$, as a replacement for the conventional filler material in hot asphalt mixtures. The X-ray diffraction test results showed that coal waste powder has pozzolanic compounds and can lead to an increase in stability and elasticity in comparison with limestone mixtures [9]. Amozadeh Omrani et al. (2018) investigated the environmental and mechanical impacts of coal fly ash and cement dust on cold Emulsified asphalt mixtures. In this study mechanical properties and environmental impacts of cement kiln dust (CKD), as a by-product of the cement and Coal Waste Ash (CWA) plant was investigated in cold recycled Asphalt mixtures (ECRM). The results showed that the use of a combination of cement kiln dust and coal waste dust can improve mechanical properties, and in some cases this improvement is more significant compared to cases where cement is added. The results of modified Toxicity Characteristic Leaching Procedure MTCLP) showed that, after five extractions, the concentration of heavy metals in the sodium mixture containing cement kilns dust and coal waste powder ash is less than the global standard levels [10]. Yilmaz et al. (2011) investigated the use of asphaltite as filler and its effect on mechanical properties of hot mix asphalts. The asphaltite used in this study was taken from the waste materials of a mine in Silopi, Turkey. In this experiment, asphaltite $(4,25,50,75$ and $100 \%)$ was replaced with limestone filler and Marshall Test was conducted in dry and saturated state. The results showed that increasing percentage of asphaltite doesn't lead to any regular increase or decrease in Asphalt stability. Moreover, the results showed that the use of 100\% asphaltite by weight of filler could increase Marshall Stability in saturated state by 30\%. Tensile strength increased by $44 \%$ and $95 \%$ in dry and saturated states respectively. Increased percentage of asphaltite as a filler, led to an increase in TSR value of the specimens [4].

Modarres et al. (2014) investigated the mechanical properties and durability of cold recycled mixtures with bitumen emulsion containing natural coal waste powder and coal powder ash. Lime was also used as a common additive in cold recycled asphalt, both separately and collectively. The results showed that the use of coal waste ash could reduce the moisture susceptibility of the recycled mixture, while coal waste would increase the moisture susceptibility of mixtures [11]. Modarres et al. (2015) investigated the effect of coal waste powder on hot mix asphalt compared to conventional fillers (a combination of mechanical properties and environmental impacts). In this study, coal waste powder, limestone, zeolite and Portland cement were used as filler. The mechanical properties and TCLP test results indicated that the use of coal waste powder as a filler in a hot mix asphalt could not only lead to more significant improvement in mechanical properties than other fillers, but also reduce the volume of the pollutants waste in environment [12]. Bayang Sueau et al. (2016) used ashes produced in coal-fired power plants as fine particles in hot mix asphalt. These ashes were used as substitutes for fine particles (passage through a $4.75 \mathrm{~mm}$ sieve) at 10, 20 and $30 \%$ proportions. The results showed that the use of coal ash, instead of fine-grained materials, could improve the performance of asphalt mixtures [13]. Sargin et al. (2013) investigated the use of rice husk ash (RHA) ash as filler in hot mix asphalt. Rice husk ash was taken from a region in Turkey and turned into ash under a temperature of $700^{\circ} \mathrm{C}$ for 4 hours. The results showed that combination of 50\% Rice husk ash and 50\% limestone provides the best result and improve the Marshall's stability. Any further increase in RHA percentage, could reduce Marshall's stability [14].

Chen et al. (2011) investigated the potential of recycled fine aggregate powder (RFAP) of limestone as a filler in hot mix asphalt. The results showed that the tensile strength of the mixtures decreases after each glacial and melting cycle, Of course, mixtures containing RFAP have a higher tensile strength than the control sample (limestone). The results indicated that specimens containing RFAP had a higher TSR than limestone [15]. Rosso dos Santos et al. (2012) used waste coal extracted from a mine in Brazil as fine-aggregate in block concrete pavement. In this research, coal waste $(0$, $25,50,75,100$ wt. \%) was replaced with sand in block concrete and compressive strength was evaluated after 7,28 and 90 days. The results showed that replacing 25 to 50 percent of waste coal with fine aggregate, provides satisfactory results in terms of mechanical strength [16]. Freitas et al. (2012) used coal waste as part of cement in a cement mix. 
According to the results, the use of $10 \%$ cement substitute increased compressive strength of 7 days but reduced the strength of 90 days [17]. Kinothia and Nidzam (2009) used coal waste to stabilize base and sub-bas. The waste coal used in this study was taken from southern England. The results indicated an increase in 7, 28 and 90 day compressive strength [18].

In the present study, attempts are made for the first time, to use fresh and old floatation waste as an additive to bitumen (to improve the bitumen properties) and as filler in asphalt mixture. In this study attempts are also made to provide the ground for asphalt aging. According to the previous sections, use of coal waste will reduce costs and energy consumption, and could be an important step towards environmental protection.

\section{Materials and Methods}

In the present study, first control specimens which consist of specimens taken from Rocky Mountains are used in order to achieve the final sample with the best performance. In the next stage, fresh and old flotation waste were used as additive and filler, and the results obtained from testing the specimens were compared to the results obtained from control sample testing. Also, the results of control specimens and old aged waste were compared.

\subsection{Aggregate}

Aggregates constitute 90 to $95 \%$ by weight and 75 to $85 \%$ by volume of the Asphalt Concrete Mixtures. The more resilient structure of aggregate materials leads to asphalt concrete mixtures with considerable strength against repetitive loading induced deformations. It has been proved that aggregates and gradation have a significant effect on the strength and performance of asphalt concrete mixtures. It is clear that the physical properties of aggregates significantly affect the performance of asphalt concrete pavements. Aggregate materials used to prepare a asphalt concrete mixture should be clean and free from any dust. Gravel and coarse-grained aggregates are the load-bearing elements in asphalt mixtures. Several factors affect the bond between bitumen and aggregate materials, for example shape of aggregates (angular or round-edged), the absorption capacity of bitumen (porous or non-porous) and the degree of acidity. The gradation of aggregate materials affect the properties of asphalt concrete mixtures, including hardness, durability, permeability, efficiency, fatigue resistance, frictional resistance, and moisture failure resistance.

Crushed aggregates are used to prepare asphalt mixtures. The gradation used in this case is a continuous gradation with a maximum size of $12.5 \mathrm{~mm}$. The gradation test was carried out according to the ASTM-D3515 standard and the results are presented in Figure 1. Topeka Limestone NO. 5 (Iranian regulation) was used in the present study. Other properties of aggregate materials are presented in Table 1.

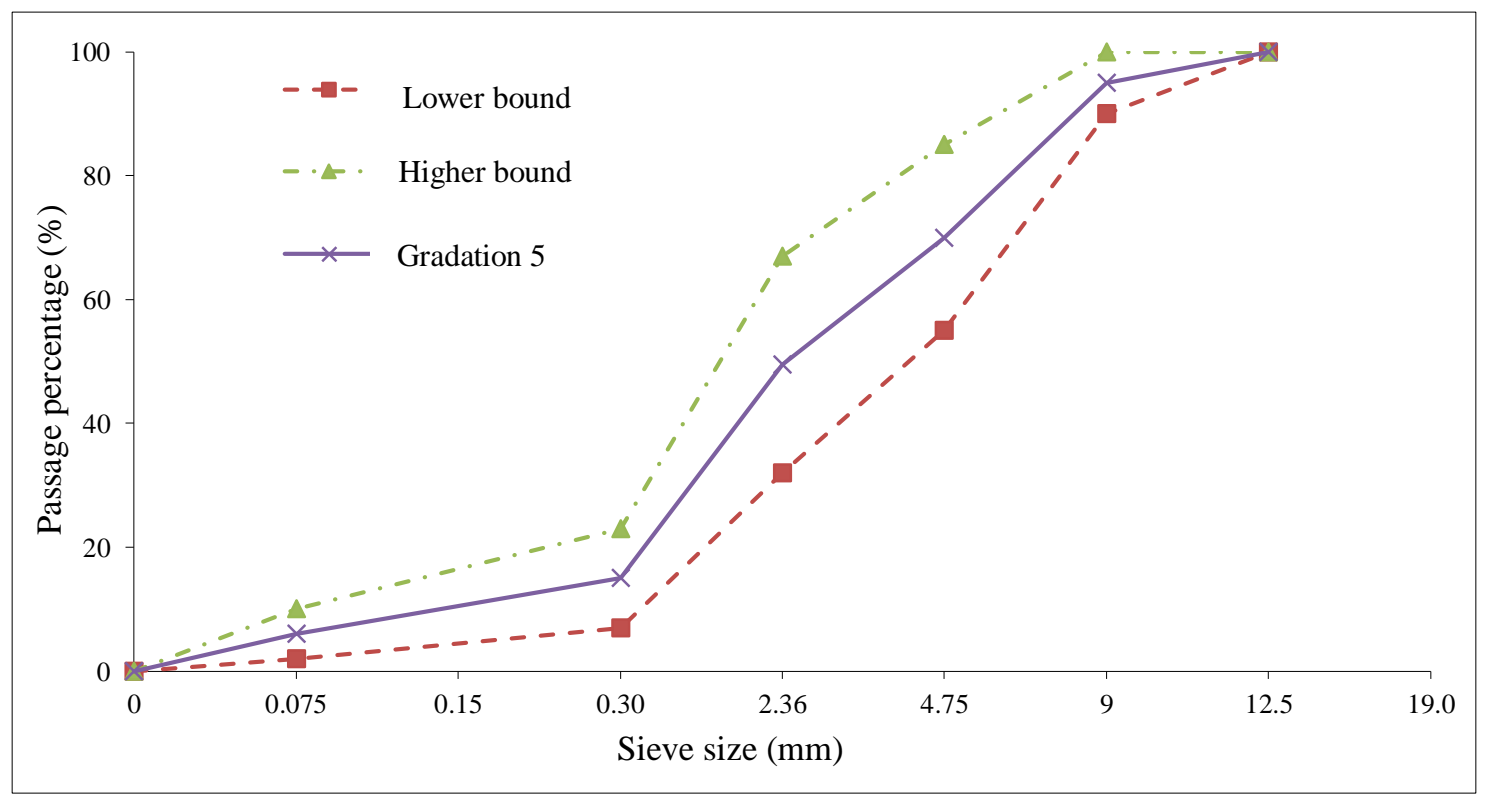

Figure 1. Gradation of aggregate materials 


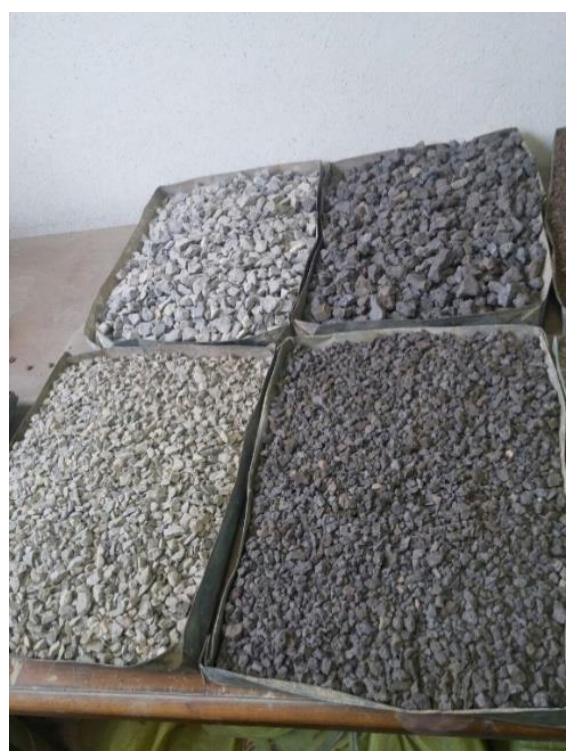

Figure 2. Different types of gradation

Table 1. Properties of aggregate materials used in the study

\begin{tabular}{cccc}
\hline Property & Standard & Unit & Result \\
\hline Los Angeles abrasion & AASHTO-T96 & $\%$ & 26 \\
Weight loss percentage when exposed to sodium sulfate & AASHTO-T104 & $\%$ & Fin engrained 0.9 Coarse-grained 0/18 \\
Specific weight & ASTM-C127 & $\mathrm{gr} / \mathrm{cm}^{3}$ & 2.63 \\
moisture absorption percentage & ASTM-C127 & $\%$ & 1.1 \\
\hline
\end{tabular}

\subsection{Bitumen}

The bitumen used in this study was purchased from Pasargad oil refinery. The bitumen is of PG 64, -16 type, and its properties are specified according to some tests. The test results are presented in Table 2. Fresh and old flotation waste was used as a bitumen additive in different specimens.

Table 2. Bitumen Specification

\begin{tabular}{cccc}
\hline Properties & Standard & Unit & Result \\
\hline Softening point & ASTM-D36 & $0 / 1 \mathrm{~mm}$ & 48 \\
Penetration Test & ASTM-D5 & ${ }^{\circ} \mathrm{C}$ & 68 \\
Ductility & ASTM-D113 & $\mathrm{cm}$ & 141.5 \\
\hline
\end{tabular}

\subsection{Coal Waste (Flotation Waste)}

As mentioned, in the present study, the waste coal taken from the coal depot unit of Central Alborz Coal Washing Plant in Savadkouh county of Mazandaran, was used to conduct the study. Equipped with non-modern Russian technology, the plant has been operating since 1368. The plant uses two Coal Washing techniques: flotation and jig processing. The waste from coal processing is depot in open space near the factory site. Mineral fillers are traditionally used in concrete asphalt mixes to fill the void space between aggregate materials. Moreover, fillers improve the mechanical properties of asphalt mixture. It should be noted that the most important role of filler in asphalt concrete mixtures is improvement of pavement life and enhancement of its resistance to water. In addition, the use of filler in asphalt concrete mixtures increases the load bearing capacity, reduces modulus of elasticity, increases impact resistance, increases the shear and compressive strength, increases viscosity and decreases brittleness. It should be noted, however, that the use of a large amount of filler in asphalt concrete mixtures can lead to reduction of porosity, increased compactness resistance and reduction of strength(due to reduced internal friction) in aggregate materials.

In the present study, limestone powder filler was used to prepare control specimens (passage through sieve. No. 200), and specimens of fresh and old coal waste powder were also used as filler. 
In the present study, limestone powder filler was used to prepare control specimens (passage through sieve. No. 200), and specimens of fresh and old coal waste powder were also used as filler.

Table 3. Chemical composition of the fresh flotation waste

\begin{tabular}{ccccccccccc}
\hline Chemical Composition & SiO2 & AL2O3 & Fe2O3 & Mgo & Cao & Na2o & K2o & Tio2 & LOI \\
\hline Percentage & 34.80 & 14.53 & 3.89 & 0.87 & 0.51 & 0.27 & 2.39 & 0.98 & 40.96 \\
\hline
\end{tabular}

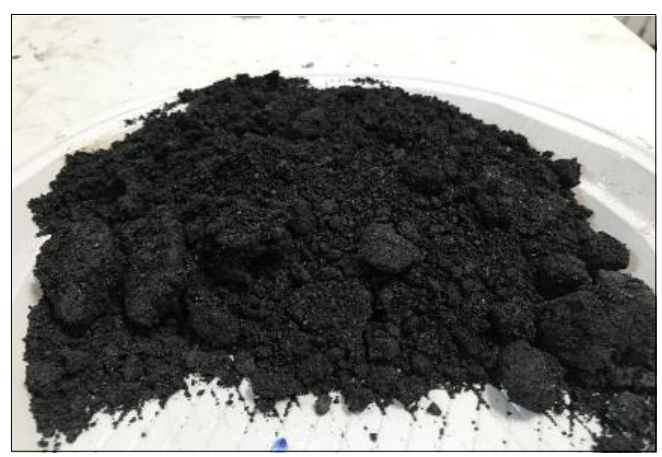

Figure 3. Fresh Flotation waste before grinding

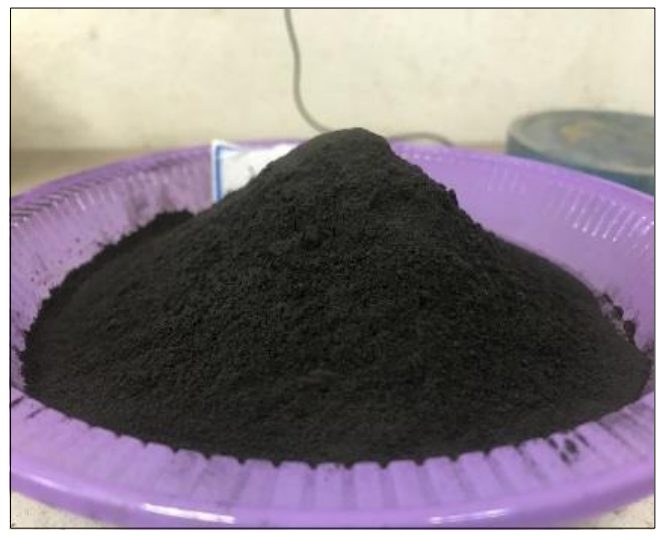

Figure 5. Fresh Flotation waste after being grinded and passed through sieve No. 200

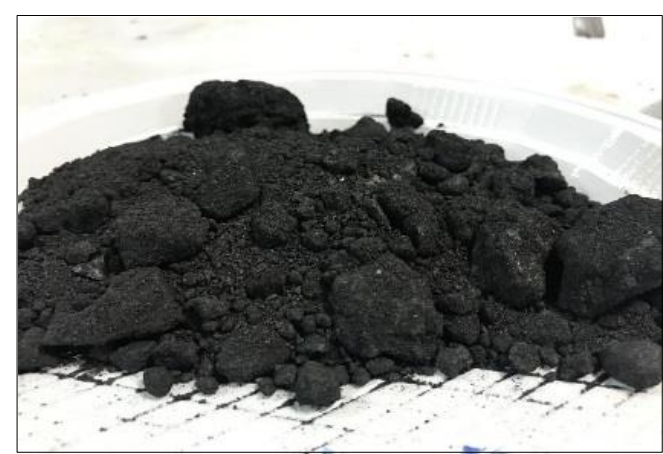

Figure 4. Old Flotation waste before grinding

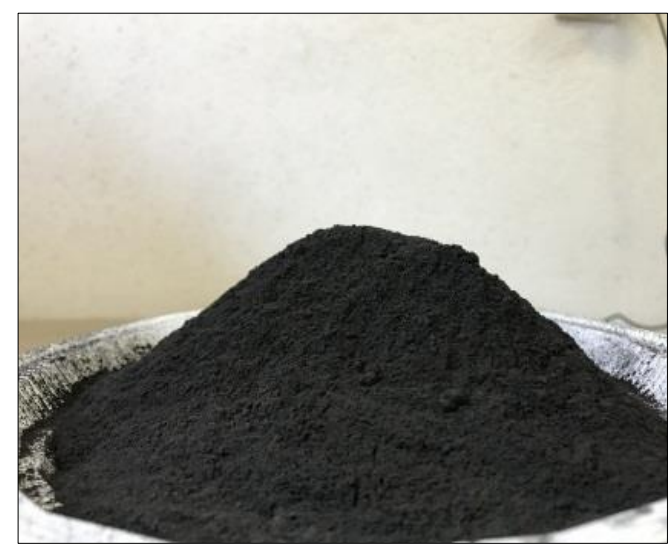

Figure 6. Old Flotation waste before being grinded and passed through sieve No. 200

\section{Experiments and Mixing Designs}

\subsection{Preparation of Specimens}

In the present study, Marshall Method was used to prepare specimens according to ASTM-D1559 standard. In this method, each cylindrical sample has a diameter of 10.6 and a height of $35.6 \mathrm{~cm}$. Fifteen specimens with 4, 5/4, 5/5, 5/5 and $6 \mathrm{wt} . \%$ Bitumen (per percentage of all three specimens) were prepared and tested according to the afore-mentioned standard. Marshall Stability, Viscosity, specific weight and Rice's specific gravity tests were used to determine optimal bitumen content. According to the results, 5 wt. \% Bitumen can be recognized as optimal bitumen.

Table 4. Introduction of the compounds prepared in this research

\begin{tabular}{ccc}
\hline Sample code & Composition of specimens & No. \\
\hline 100 & Specimens made of mountain rock control sample) & 12 \\
110 & Fresh Flotation waste used as bitumen additive (7\% by weight of bitumen) & 12 \\
120 & Old Flotation waste used as bitumen additive (7\% by weight of bitumen) & 12 \\
130 & Fresh Flotation waste used as filler(100\% filler substitute) & 12 \\
140 & old Flotation waste used as filler(100\% filler substitute) & 12 \\
\hline
\end{tabular}




\subsection{Marshall Stability}

Marshall Stability is one of the basic parameters used in the design of asphalt concrete mixtures. The Marshall's stability is the maximum load that can be tolerated by the sample specimen before fracture under Marshal Apparatus. After preparing dry specimens, they should be submerged in a 60-degree water bath for 30 - 40 minutes and then tested for Marshall Stability.

The Marshall Flow test accounts for vertical deformation of the tested specimens from the beginning of the loading up to the point the specimen breaks. In this test, the flow values are determined according to standard of ASTM-D1559

In Figure 7, the specimen is placed in a bin Mary bath at a temperature of $60{ }^{\circ} \mathrm{C}$, and Figure 8 , shows a specimen of asphaltic mixtures subjected to the Marshall Stability test.

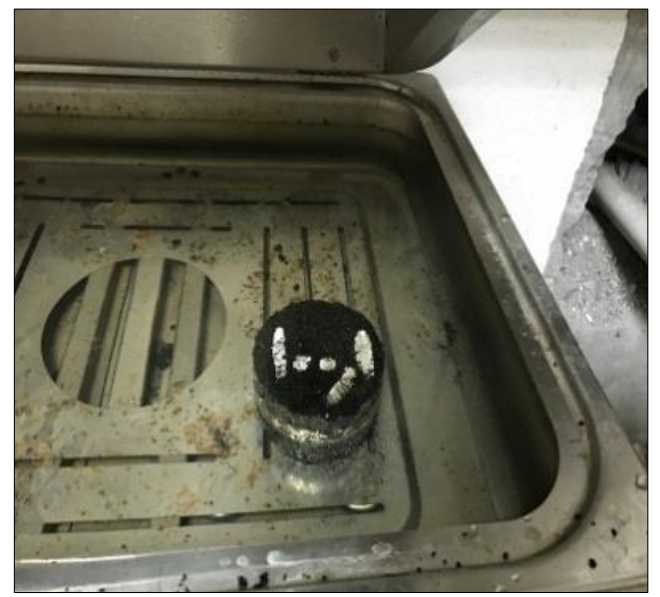

Figure 7. The specimen placed in a bin Mary bath at a temperature of 60 degrees

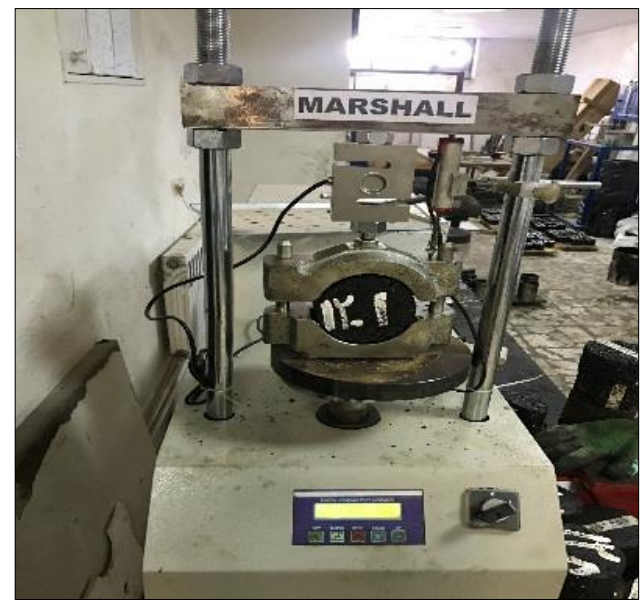

Figure 8. The specimen subjected to Marshall Stability Test

\subsection{Indirect Tensile Strength Test}

Indirect tensile testing has been widely used for designing flexible pavement structures since the 1960s. In this test, a cylindrical specimen is subjected to diagonal loading. The test result is used to determine the tensile strength of the asphalt mixtures. In this study, indirect tensile test was performed according to AASHTO-T283.03 standard. Figure 11 shows a schematic view of the loading method.

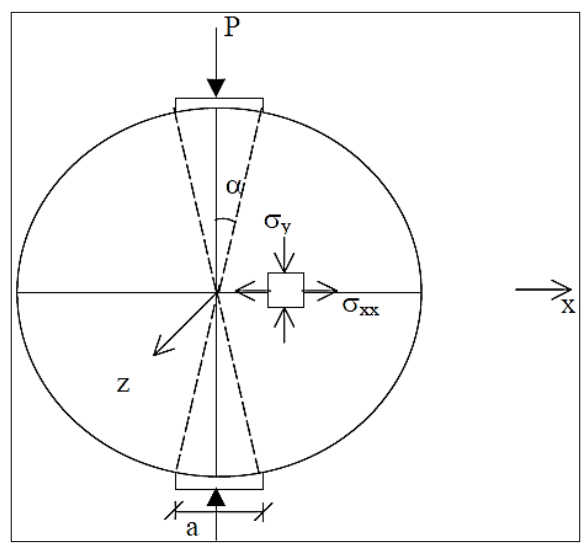

Figure 9. Schematic view of force exertion in the indirect tensile test

Indirect tensile testing is used to determine the tensile properties of asphalt concrete mixtures that are associated with the pavement cracking properties. Specimens made according to the AASHTO-T283 standard were first submerged in a 25-degree water bath for 2 hours and then subjected to an ITS test. Figure 12, shows the specimen subjected to the ITS test.

The following equation is used to determine the tensile strength according to the value of force $\mathrm{P}$ presented on the device:

$$
S_{t}=\frac{2000 P}{\pi t D}
$$


Where $\mathrm{P}$ is the amount of load, $\mathrm{t}$ shows the thickness, $\mathrm{D}$ is the specimen's diameter and $\mathrm{St}$ is the tensile strength $(\mathrm{KPa})$.

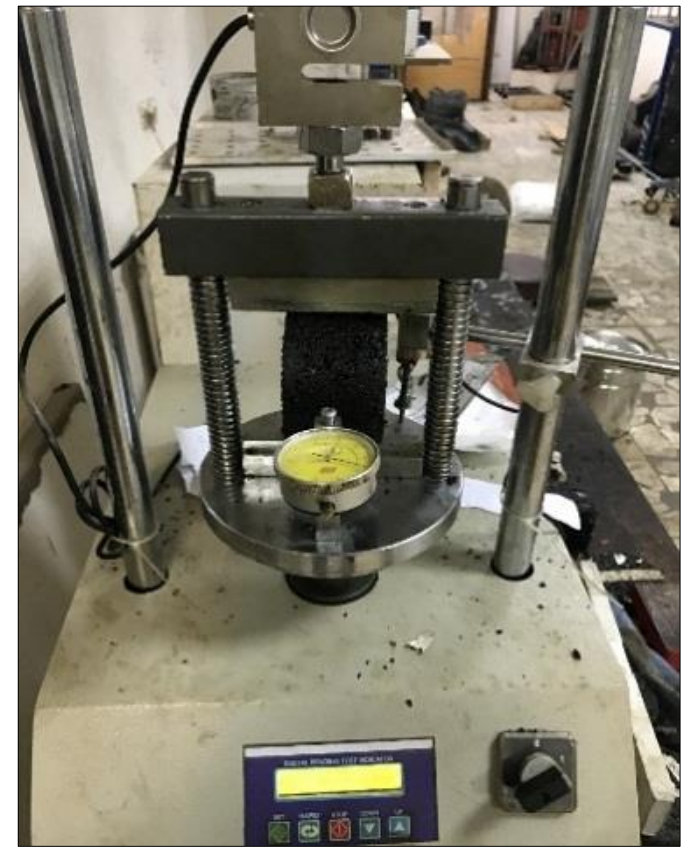

Figure 10. Specimen subjected to indirect tensile test

\subsection{Applying Aging in Laboratory Conditions}

Short-term and long-term aging can be applied in two ways:

- Applying aging to bitumen

- Applying aging to the bitumen and aggregate mixture

The aging of asphalt mixture is also affected by the type of bitumen and materials. Bitumen aging alone cannot serve as an acceptable factor for predicting the performance of Asphalt mixture, and the type of aggregate materials can also affect this process.

Therefore, the second approach (Applying aging to the bitumen and aggregate mixture) was used in this research. In addition, since, according to the literature, oven aging is the most suitable method for aging, oven aging (according to standard AASHTO-R30) was used to apply short-term aging.

The AASHTO-R30 standard for short-term aging involves asphalt mixture aging in oven for 4 hours at $135^{\circ} \mathrm{C}$. In this process, the asphalt mixture should be stirred once in every hour.

\section{Results and Discussion}

Marshall Stability Test Studies have shown that specimen with neither too fine nor too coarse gradation (medium gradation) show maximum strength. In this state, the specimen can get the most out of the binding between aggregates in the first hand and can contain adequate amount of fine aggregates to prevent creation of too many void spaces and loose mixtures on the second hand. Considering the shape of the Marshall Compression tester's jaw, the manner in which loading is applied, and the placement of specimens, this argument seems quite logical. Given that the Marshall Test is classified as an empirical test and considering the limited application of this tester due to lack of direct relation between the test output and asphalt mixture performance, the strength and flow test results obtained using the Marshall Compression tester cannot provide us with any acceptable solutions regarding the output of the fatigue test, indirect tensile test, etc. the Marshall stability Test graph for control specimens, specimens containing fresh and old flotation additive, and specimens containing fresh and old flotation filler in both aging and short-term aging conditions are presented below.

Figures 11 and 12, show the results of the Marshall stability Test for the various un-aged and short-term aged asphalt mixtures. According to the figures, Marshall Stability range is between 813 to $1131 \mathrm{~kg}$ that actually exceeds the minimum value specified in the regulations for heavy traffic $(800 \mathrm{~kg})$ for all specimens in both un-aged and short-term aged conditions. The highest level of Marshall Stability in the un-aged condition is related to of the fresh flotation waste used as bitumen additive. 


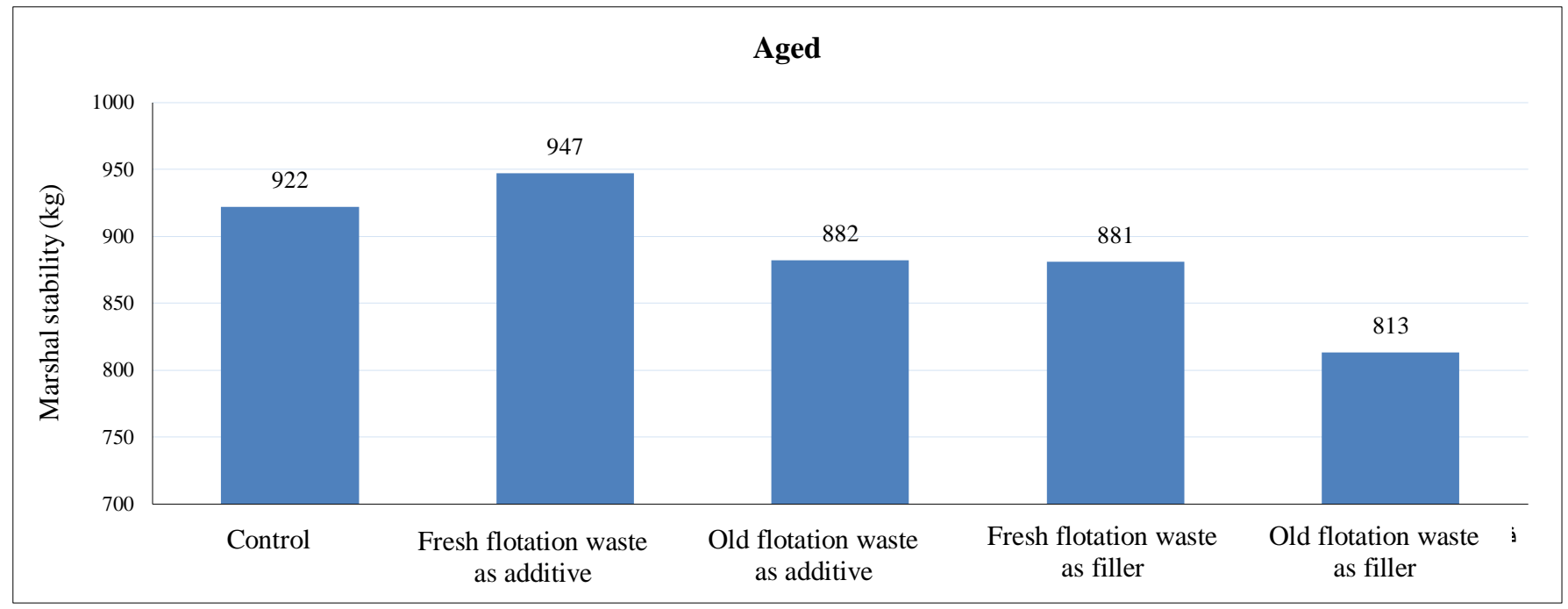

Figure 11. Graph of Marshall Stability variations in un-aged Condition

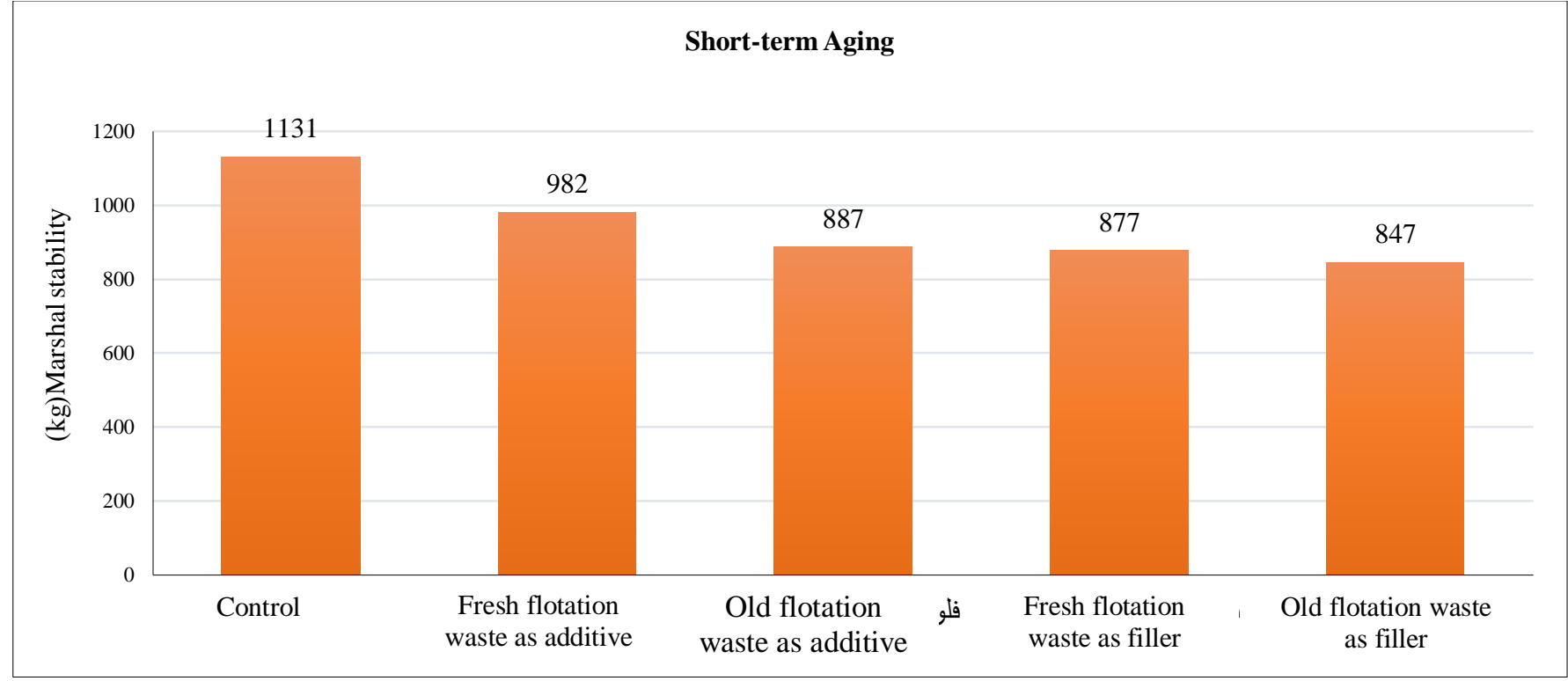

Figure 12. Graph of Marshall Stability variations in short-term aging Condition

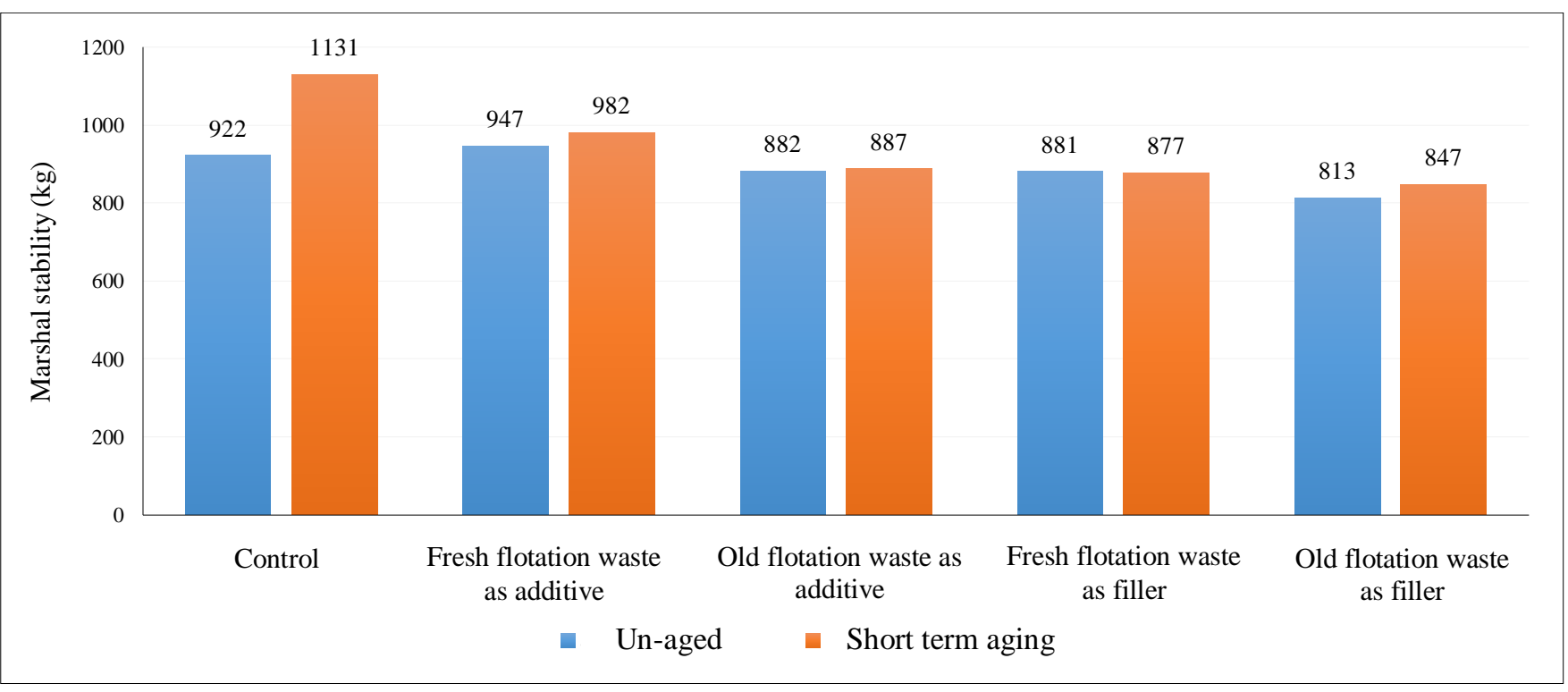

Figure 13. Graph of Marshall Stability variations in un-aged and short-term aging Conditions 
According to Figure 13, the point to note about the effect of aging on the Marshall stability of different specimens is that aging has a greater effect on the control specimens compared to other specimens containing flotation waste additive or filler. The figure also indicates that aging increases the Marshall stability and decreases the flow number compared to the values of un-aged specimens, which can be attributed to the increased hardness of bitumen during the aging process and, consequently, increased hardness of the asphalt mixture. In fact, the material used, both as a filler and as an additive, helps preserve the molecular structure of bitumen in aging conditions as compared to the control specimen.

According to Figure 14, the results of the indirect tensile test on different un-aged specimens indicate that fresh flotation waste, both as a filler and as an additive, increases the tensile strength compared to control specimens and the old flotation waste (as additive and Filler).

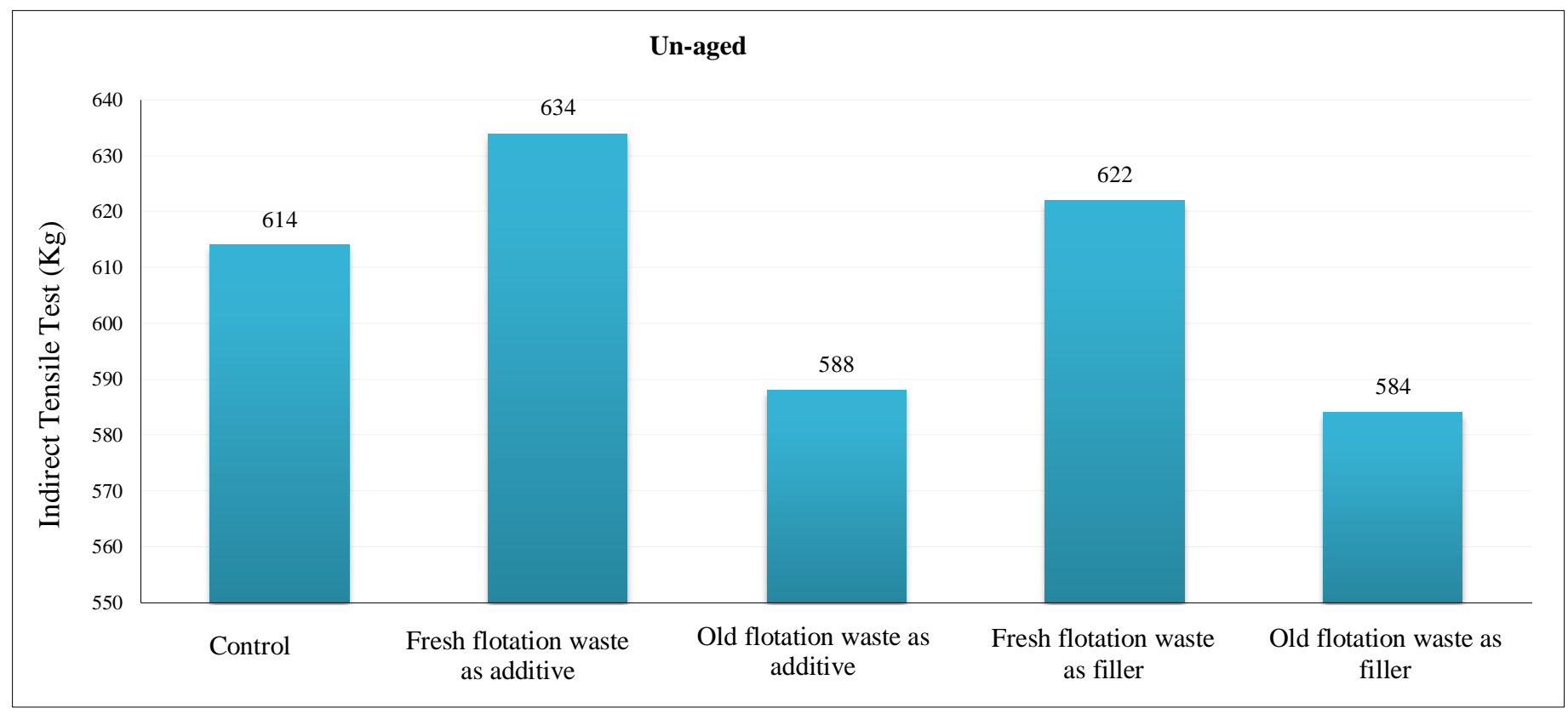

Figure 14. Indirect tensile strength variations in un-aged condition

According to Figure 15, the fresh and old flotation waste (used both as additive and the filler) have a better tensile strength than the control specimens. Moreover, the fresh flotation waste used both as additive and filler enjoys a higher tensile strength compared to the old flotation waste specimens used as additive and filler.

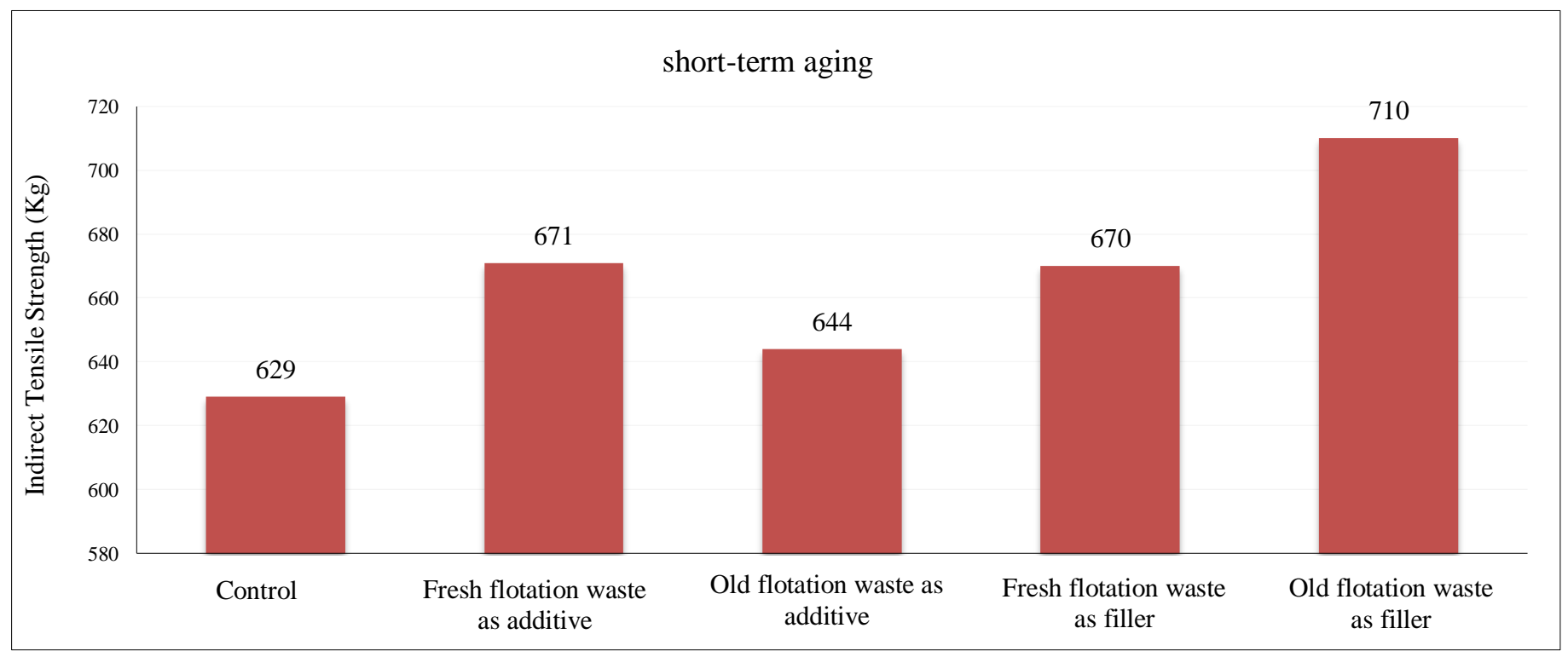

Figure 15. Indirect tensile strength variations in short-term aging condition

According to Figure 16, the results obtained in un- aged and short-term aging conditions indicate that the fresh and old floatation waste improves the indirect tensile strength of mixtures subjected to short-term aging conditions. 


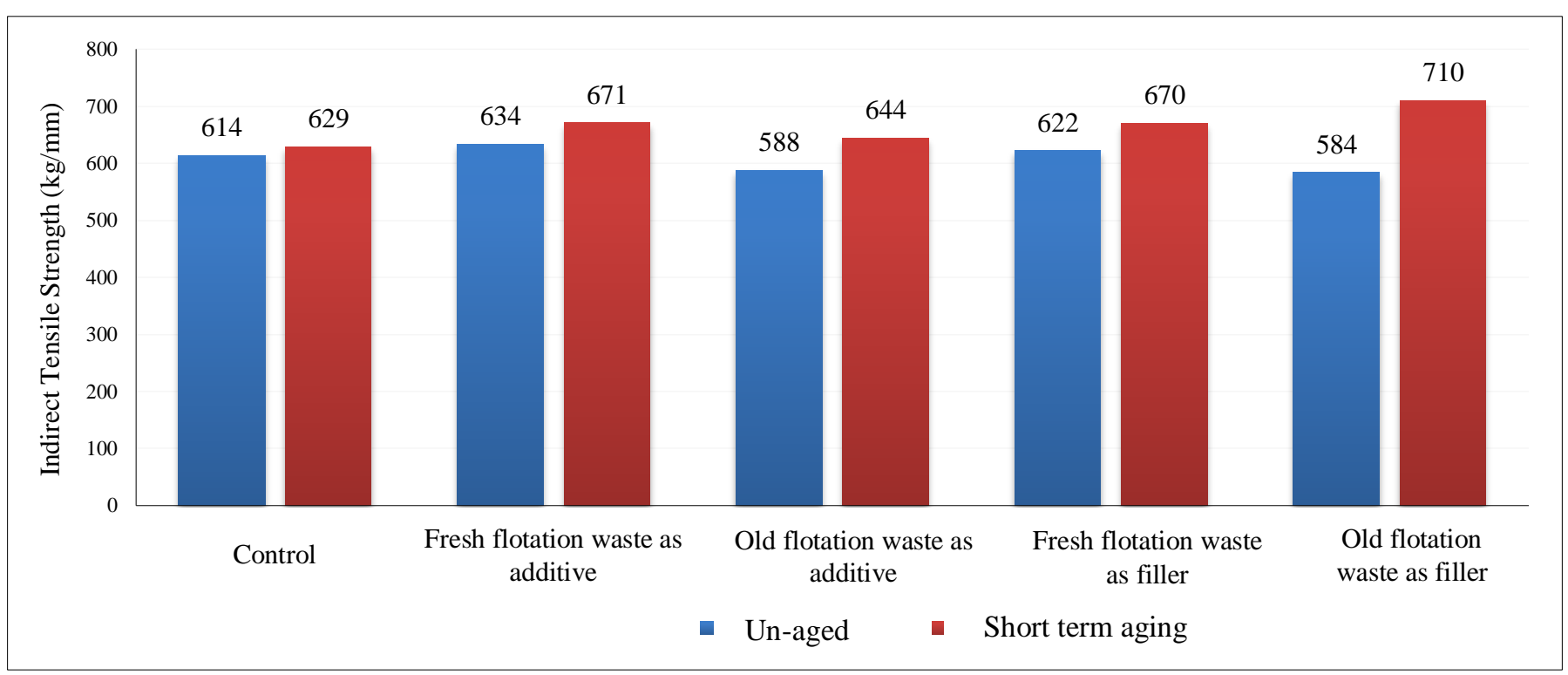

Figure 16. Comparison of indirect tensile strength in un-aged and short-term ageing conditions

\section{Conclusions}

In the present study, some experiments were carried out to investigate the feasibility of using the old and fresh flotation waste as additive and filler in hot mix asphalt. After determining the optimum bitumen (5\%), fresh and old Floatation waste $100 \%$ by weight of filler and $7 \%$ by weight of bitumen was used as additive and the obtained results were compared. The most important results of the present study are as follows:

- In all tested specimens, Marshall Stability Number exceeded the minimum value specified in regulations for high traffic $(800 \mathrm{~kg})$.

- The noteworthy point about the effect of aging on the Marshall stability of different specimens indicates that aging has a greater effect on the control specimens compared to other specimens containing additive or coal waste dust filler. The results also indicates that aging increases the Marshall stability and decreases the flow number of specimens as compared to the old specimens, and this can be due to the increased hardness of bitumen during the aging process and, consequently, increased hardness of the asphalt mixture. In fact, the material used, both as a filler and as an additive, helps preserve the molecular structure of bitumen in aging conditions as compared to the control specimen.

- The results of indirect tensile test on different unpaged specimens show that the old flotation waste declines indirect tensile strength of the specimens and this could be attributed to the amorphous structure of the materials and their effect on the molecular chain of asphalt mixtures.

- the results of tests on specimens subjected to short-term aging conditions shows the negative effect of aging on tensile strength of old flotation specimens, which is indicative of the fact that this material increases the effect of aging on the asphalt mixture.

- The results obtained from various conditions (un-aged, short-term aging and long-term aging) indicate that the oldfresh flotation wastes improve the tensile strength of mixtures subjected to short-term and long-term aging conditions.

\section{References}

[1] Muniandy, R, E Aburkaba, and R Taha. "Effect of Mineral Filler Type and Particle Size on the Engineering Properties of Stone Mastic Asphalt Pavements." The Journal of Engineering Research [TJER] 10, no. 2 (December 1, 2013 ): 13. doi:10.24200/tjer.vol10iss2pp13-32.

[2] Serin, Sercan, Nihat Morova, Mehmet Saltan, and Serdal Terzi. "Investigation of Usability of Steel Fibers in Asphalt Concrete Mixtures.” Construction and Building Materials 36 (November 2012): 238-244. doi:10.1016/j.conbuildmat.2012.04.113.

[3] Yan, Ke-zhen, Hong-bin Xu, and Heng-long Zhang. "Effect of Mineral Filler on Properties of Warm Asphalt Mastic Containing Sasobit." Construction and Building Materials 48 (November 2013): 622-627. doi:10.1016/j.conbuildmat.2013.07.085.

[4] Yilmaz, Mehmet, Baha Vural Kök, and Necati Kuloğlu. "Effects of Using Asphaltite as Filler on Mechanical Properties of Hot Mix Asphalt." Construction and Building Materials25, no. 11 (November2011): 4279-4286. doi:10.1016/j.conbuildmat.2011.04.072.

[5] Papagiannakis, A. T., and E. A. Masad. "Pavement Design and Materials" (July 19, 2012). doi:10.1002/9780470259924. 
[6] Tahirou, M. "Influence of Bitumen Ageing on Asphalt Quality, Comparison between Bitumen and Asphalt Ageing." A MSc Thesis in Physical Land Resources, Inter University Programme of Universiteit Gent and Vrije Universiteit Brussel, Belgium. Pg 13 (2009).

[7] BIAN, Zhengfu, Hilary I INYANG, John L DANIELS, Frank OTTO, and Sue STRUTHERS. "Environmental Issues from Coal Mining and Their Solutions.” Mining Science and Technology (China) 20, no. 2 (March 2010): 215-223. doi:10.1016/s16745264(09)60187-3.

[8] Doulati Ardejani, Faramarz, Behshad Jodieri Shokri, Ali Moradzadeh, Seyed Ziadin Shafaei, and Reza Kakaei. "Geochemical Characterisation of Pyrite Oxidation and Environmental Problems Related to Release and Transport of Metals from a Coal Washing Low-Grade Waste Dump, Shahrood, Northeast Iran." Environmental Monitoring and Assessment 183, no. 1-4 (February 26, 2011): 41-55. doi:10.1007/s10661-011-1904-2.

[9] Modarres, Amir, and Morteza Rahmanzadeh. "Application of Coal Waste Powder as Filler in Hot Mix Asphalt." Construction and Building Materials 66 (September 2014): 476-483. doi:10.1016/j.conbuildmat.2014.06.002.

[10] Amouzadeh Omrani, Mohsen, and Amir Modarres. "Emulsified Cold Recycled Mixtures Using Cement Kiln Dust and Coal Waste Ash-Mechanical-Environmental Impacts.” Journal of Cleaner Production 199 (October 2018): 101-111. doi:10.1016/j.jclepro.2018.07.155.

[11] Modarres, Amir, and Pooyan Ayar. "Coal Waste Application in Recycled Asphalt Mixtures with Bitumen Emulsion.” Journal of Cleaner Production 83 (November 2014): 263-272. doi:10.1016/j.jclepro.2014.07.082.

[12] Modarres, Amir, Morteza Rahmanzadeh, and Pooyan Ayar. "Effect of Coal Waste Powder in Hot Mix Asphalt Compared to Conventional Fillers: Mix Mechanical Properties and Environmental Impacts." Journal of Cleaner Production 91 (March 2015): 262268. doi:10.1016/j.jclepro.2014.11.078.

[13] Yoo, Byung-Soo, Dae-Wook Park, and Hai Viet Vo. "Evaluation of Asphalt Mixture Containing Coal Ash." Transportation Research Procedia 14 (2016): 797-803. doi:10.1016/j.trpro.2016.05.027.

[14] Sargın, Şebnem, Mehmet Saltan, Nihat Morova, Sercan Serin, and Serdal Terzi. "Evaluation of Rice Husk Ash as Filler in Hot Mix Asphalt Concrete." Construction and Building Materials 48 (November 2013): 390-397. doi:10.1016/j.conbuildmat.2013.06.029.

[15] Chen, Meizhu, Juntao Lin, and Shaopeng Wu. "Potential of Recycled Fine Aggregates Powder as Filler in Asphalt Mixture." Construction and Building Materials 25, no. 10 (October 2011): 3909-3914. doi:10.1016/j.conbuildmat.2011.04.022.

[16] Santos, Cassiano Rossi dos, Juarez Ramos do Amaral Filho, Rejane Maria Candiota Tubino, and Ivo André Homrich Schneider. "Use of Coal Waste as Fine Aggregates in Concrete Paving Blocks." Geomaterials 03, no. 02 (2013): 54-59. doi:10.4236/gm.2013.32007.

[17] Frías, M., M.I. Sanchez de Rojas, R. García, A. Juan Valdés, and C. Medina. "Effect of Activated Coal Mining Wastes on the Properties of Blended Cement." Cement and Concrete Composites 34, no. 5 (May 2012): 678-683. doi:10.1016/j.cemconcomp.2012.02.006.

[18] Kinuthia, J., and R. Nidzam. "Effect of slag and siliceous additions on the performance of stabilized coal waste backfill." In WorZd of Coal Ash (WOCA) Conference, Lexington, KY, USA. 2009. 